\title{
PRUEBA DE LA BOLSA DE HIELO: UNA PISTA CLÍNICA PARA MIASTENIA GRAVIS
}

\section{ICE PACK TEST: A CLINICAL CLUE FOR MYASTHENIA GRAVIS}

\section{Rueda Borrero, Elsa*}

*Médico Residente del Servicio de Medicina Interna, Complejo Hospitalario “Dr. Arnulfo Arias Madrid”, Ciudad de Panamá

"Rueda E, Prueba de la bolsa de hielo: una pista clínica para miastenia gravis. Rev méd cient. 2020; Volumen (33): 16-17. DOI: 10.37416/rmc.v33i1.545"

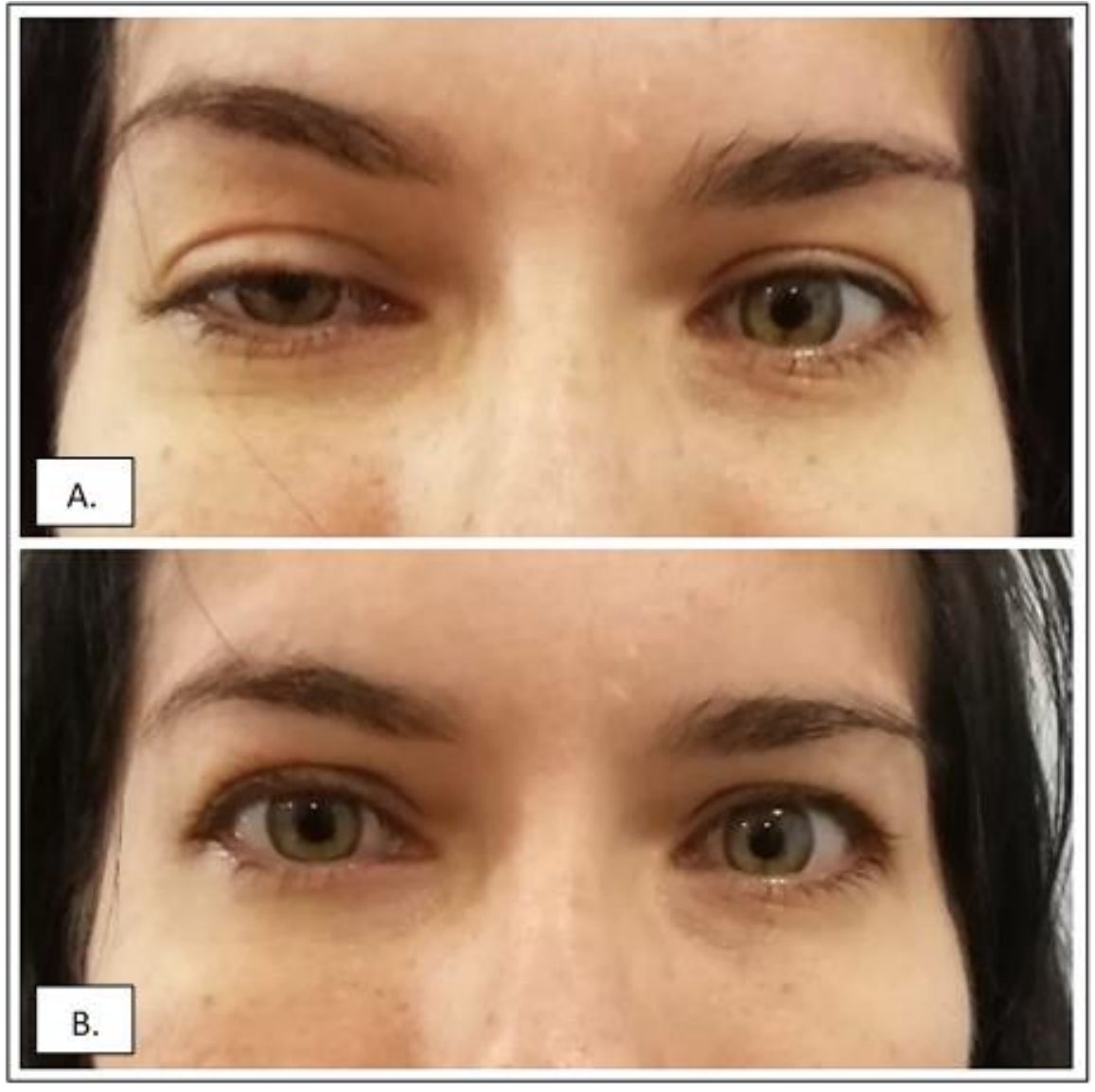

Figura 1. Panel A: Ptosis del ojo derecho con hendidura palpebral de $7 \mathrm{~mm}$. Panel B: Resultado después de la aplicación de la Prueba de la Bolsa de Hielo. La hendidura palpebral aumentó a $12 \mathrm{~mm}$.

[Prueba de la Bolsa de Hielo: Una Pista Clínica para Miastenia Gravis By Rueda E is licensed under a https://creativecommons.org/licenses/by-nc-nd/4.0. Permissions beyond the scope of this license may be available at www.revistamedicocientifica.org. 
Paciente femenina de 30 años sin antecedentes personales acude por historia de 6 meses de evolución de ptosis palpebral derecha asociada a visión borrosa, fatiga constante con particular pesadez de miembros inferiores y en las últimas dos semanas desarrollo de disfagia orofaríngea ocasional para sólidos y líquidos.

Al examen físico los hallazgos fundamentales fueron la blefaroptosis derecha, tremor ocular bilateral y disminución de la fuerza en grupos musculares proximales de los miembros inferiores. Se consideró que se pudiese tratar de un Síndrome Miasténico Generalizado debido a la debilidad muscular y manifestaciones oculares y bulbares, por lo que la impresión diagnóstica principal fue una enfermedad de la placa neuromuscular.

En la literatura médica existen pruebas de extensión neurológica de realización rápida que orientan con alto nivel de evidencia a Miastenia Gravis (MG). La prueba de la bolsa de hielo, descrita en 1979 por Salvedra, consiste en aplicar una bolsa o guante con hielo en el párpado cerrado del paciente por dos minutos, siendo positiva si luego de pasado el tiempo hay mejoría de la ptosis, la cual se objetiva por el aumento $>2 \mathrm{~mm}$ de la hendidura palpebral (ver Figura 1). ${ }^{1}$ Esta maniobra posee una elevada Razón de Verosimilitud, conocida como Likelihood Ratio (LR) en inglés, LR+ 24,0; LR- 0,16. ${ }^{2}$

Se confirmó el diagnóstico de MG con niveles serológicos altos de anticuerpo anti-receptor de acetilcolina y electromiografía de estimulación repetitiva que mostró disminución de la amplitud del potencial de placa terminal. ${ }^{3,4}$ No hubo hallazgos en la tomografía de tórax, por lo que se descartó relación con anormalidades del timo. ${ }^{3}$ Se inició Piridostigmina 30 mg VO TID con mejoría de los síntomas y se brindó citas de seguimiento con el servicio de Neurología.

\section{REFERENCIAS:}

1. McGee S. Evidence-Based Physical Diagnosis. 4th Ed. Filadelfia: Elsevier, 2018.

2. Scherer K, Bedlack R, Simel D. Does This Patient Have Myasthenia Gravis? JAMA [Internet]. $2005 ; 293$ (15): 1906-14. Disponible en: https://jamanetwork.com/journals/jama/article-abstract/200737

3. Gilhus N, et al. Myasthenia Gravis. Nature [Internet]. 2019; 5 (30): 1-19. Disponible en: https://www.nature.com/articles/s41572-019-0079-y

4. Gilhus N, Verschuuren J. Myasthenia gravis: subgroup classification and therapeutic strategies. Lancet Neurol [Internet]. 2015; 14: 1023-36. Disponible en: https://www.thelancet.com/journals/laneur/article/PIIS1474-4422(15)00145-3/fulltext 